Filología y Lingüística 46 (1): 314-316

Abril - Setiembre 2020

ISSN: 0377-628X / EISSN: 2215-2628

Doi: https://doi.org/10.15517/rfl.v46i1.41227

URL: https://revistas.ucr.ac.cr/index.php/filyling

\title{
Carla Victoria Jara Murillo. Gramática de la lengua bribri. San José: E-Digital ED, 2018, 271 páginas
}

Con excepción de un pequeño vocabulario fechado en 1788-1790, en el que figuran varias palabras del "viceyta" -uno de los glotónimos con los que se conocía el bribri durante la época colonial-, la tradición de documentación y descripción de la lengua bribri se remonta realmente a finales del siglo XIX, cuando vieron la luz las primeras recopilaciones léxicas relativamente sistemáticas y los primeros ensayos de descripción de la gramática y de la fonética de este idioma. No obstante, la descripción lingüística propiamente profesional comenzará a finales de la década de 1970 y, en particular -sin restarles relevancia a artículos y libros previos- se verá plasmada en dos textos fundamentales para el conocimiento de esta lengua: el Diccionario fraseológico bribri-español/español-bribri de Enrique Margery Peña (cuya primera edición data de 1982 por la Editorial de la Universidad de Costa Rica) y el Curso básico de bribri de Adolfo Constenla Umaña, Feliciano Elizondo Figueroa y Francisco Pereira Mora (1998, Editorial de la Universidad de Costa Rica). En esta ingente tradición se inserta la Gramática de la lengua bribri de la Dra. Carla Victoria Jara Murillo, la obra de quien ha dedicado aproximadamente tres décadas al estudio del idioma y de la tradición oral del pueblo bribri.

No se trata, por consiguiente, de una descripción realizada con premura, a partir de un contacto casual con un hablante o con base en un texto recogido en una visita "paracaidística" a la comunidad. Por el contrario, se trata de una gramática surgida tras arduos años de estudio y enseñanza del idioma, de enfrentarse a la transcripción de grabaciones, de sistematizar aspectos concretos de la morfosintaxis y del discurso, de realizar trabajo de campo, de colaborar en la corrección de materiales didácticos, de intentar desentrañar los más profundos secretos del funcionamiento de la lengua y de analizar de forma detallada textos de muy diversa naturaleza. He de señalar al menos seis características que hacen de esta gramática un trabajo de enorme valor.

En primer lugar, se basa en un corpus monolingüe de 22600 palabras, proveniente de textos grabados con siete hablantes de dos generaciones: cuatro monolingües de más de 60 años y tres bilingües de menos de 40 años, de dos de las grandes variedades del bribri (Coroma y Amubre). Los textos que conforman este corpus corresponden a discurso narrativo, descriptivo, conversacional e instructivo. Por lo tanto, se trata de un corpus poligeolectal, transgeneracional y multidiscursivo. Esto le permite a la autora describir usos geolectales divergentes, ejemplificar con formas realmente producidas en el discurso y realizar estimaciones acerca de la productividad y frecuencia de los recursos lingüísticos de los que da cuenta.

En segundo lugar, se propone un diálogo constante con descripciones de lingüistas predecesores y contemporáneos. En particular, a lo largo de toda la obra, la Dra. Jara alude sin mezquindades académicas al aporte del Dr. Adolfo Constenla Umaña, a sus sistematizaciones y a sus explicaciones. A veces complementa y amplía sus observaciones, otras veces cita sus análisis, a veces se apega a sus descripciones y otras se aparta de estas respetuosamente 
cuando sus datos le indican algo distinto o cuando considera mejores otras opciones en aspectos tan variados como, por ejemplo, la terminología y la representación gráfica. El que en su Gramática se sistematicen en forma de cuadros los recursos lingüísticos documentados por Constenla, a la par de que se agreguen nuevas formas y nuevas sistematizaciones de su propia cosecha, hace que la obra resulte de una riqueza difícilmente superable. En este sentido, la Gramática de la lengua bribri ofrece la descripción más comprehensiva y actualizada de la morfosintaxis de este idioma.

En tercer lugar, si bien la descripción presentada en la obra rescata lo mejor de la tradición estructuralista, ciertamente la autora hace gala de la perspectiva funcionalista como marco de acercamiento a la lengua, sin caer en apegos malsanos a una corriente teórica. Además, la autora no se ciñe tampoco a una forma preestablecida de sistematizar la gramática ni a la tradición descriptiva de sus predecesores. Por el contrario, por ejemplo, propone su propia sistematización de clases de palabras en bribri basándose en criterios semánticos, fonológicos y morfosintácticos explícitos: clases mayores (sustantivos, verbos, modificadores, ideófonos e interjecciones) y clases menores (pronombres y demostrativos, existenciales / estativos, posposiciones, y conjunciones y partículas).

La descripción es técnica y rigurosa; sin embargo, la autora procura proporcionarle al lector no especializado las herramientas terminológicas y de análisis indispensables para seguir la exposición, muchas veces mediante la estrategia de explicar y ejemplificar los fenómenos gramaticales en español, para luego, de modo contrastivo, pasar al bribri.

En cuarto lugar, aunque la mayor parte del texto se dedique a la descripción de la morfosintaxis, no están ausentes las secciones esclarecedoras de fonología, de discurso y acerca de la situación sociolingüística de la lengua, así como diversas aclaraciones en las líneas etnosemántica, etnográfica, tipológica y genealógica. En particular, los apuntes que asocian lengua y cultura enriquecen la exposición y sugieren perspectivas más completas de enfrentar el análisis lingüístico. Además, el cuerpo central del libro termina con un capítulo en el que se tratan y ejemplifican cuatro tipos de discurso con textos glosados y traducidos, a modo de ilustración tanto de diversas modalidades discursivas típicas de la cultura bribri como del empleo de las estructuras y recursos gramaticales en unidades mayores a la oración.

En quinto lugar, el texto está redactado con suma claridad y sin escatimar en recursos de apoyo para seguir la exposición. En este sentido, se agradecen profundamente los múltiples ejemplos glosados y traducidos, así como la presencia ubicua de cuadros en los que se recogen sistemáticamente los recursos lingüísticos estudiados en cada sección. Los anexos no son menos valiosos a este respecto: el libro cierra con listas extensas de oposiciones fonológicas ejemplificadas, con anotaciones sobre las realizaciones alofónicas y con consideraciones acerca de la estructura silábica, así como con largas listas de verbos clasificados y conjugados.

Estos anexos, así como los cuadros y los ejemplos en el cuerpo del libro, evidencian la profundidad con la que la autora ha logrado sistematizar el funcionamiento y los recursos de la lengua, su conocimiento a la vez global y a la vez minucioso acerca del idioma y, sobre todo, su esfuerzo por transmitir de manera accesible algo tan complejo y sofisticado como la descripción de las estructuras y los sistemas morfosintácticos del bribri.

En sexto lugar, valga subrayar un detalle que podría pasar inadvertido, pero que en realidad revela la alta calidad de la obra: la Dra. Jara incursiona en la creación de terminología lingüística para referirse a las clases de palabras bribris en la propia lengua, con base en el 
conocimiento profundo de sus recursos formales y de la cultura, con lo cual inicia un tipo de planificación no desarrollada aún con respecto a las lenguas de Costa Rica.

Por todo lo anterior, no cabe duda de que, además de constituirse en texto de consulta obligatoria para la descripción y el análisis de la morfosintaxis del bribri, esta obra de la Dra. Jara será de utilidad directa en la formación de maestros de lengua bribri, así como en la creación de recursos didácticos y de propuestas pedagógicas para los procesos de enseñanzaaprendizaje del idioma. Dado que el bribri constituye una lengua en acelerado proceso de desplazamiento, no puede más que celebrarse la publicación de una descripción lingüística de semejante calidad y profesionalismo.

Carlos Sánchez Avendaño Universidad de Costa Rica San José, Costa Rica 